PARtake: The Journal of Performance as Research

Volume 3, Issue 2 - March 2021

ISSN: $2472-0860$

\title{
Theatre Island and Urban Scenographies of Learning: A Performative Paradigm for Transversal Pedagogy
}

\author{
Shauna Janssen, $\mathrm{PhD}$ - Concordia University
}

Special thanks to Kristine Samson (Associate Professor in Performance Design at Roskilde) for introducing me to Teaterøen in the first place, as a guest speaker in her performative urbanism course (2018); to our hosts at Theatre Island/Teaterøen, Peter Kirk and Tilde Knudsen; the Faculty of Fine Arts Dean's office for managing the Thomson Gift which helped to support student scholarships; the team at Concordia International for administrative assistance; and not least of all, the students, for their openness, curiosity and creativity: Imogen Blomley, Brent Cleveland, Lucy Earle, Paule Gilbert, Sara Jarvie-Clark, Katrina Jurjans, Devon McKellar, Merlin Platt, Jonathan Stern, Jenn Townsend, Abigail Stushnoff and Yuxiang Wang. 
Is the interdisciplinary operator one who straddles two places, one who maps the tears and rifts, the places where things have come apart, and the overlaps and the joins, the places where things come together? Or has s/he come from elsewhere, arrived as a stranger in town? Being someone new in town is a different experience altogether. Here one place has been left and a new unknown terrain entered. What do you do? Match the new to meet up with the standards of the old, or allow yourself to be changed by your new surroundings? ${ }^{1}$

\section{Introduction}

In this essay I describe a performative paradigm for transversal pedagogy that takes seriously a field school on "urban scenography" as a site for experiential, interdisciplinary and collaborative learning. More to the point, I am interested in a transversal pedagogy that generates questions rather than teaching solutions, marking critically the importance of acknowledging and making spaces for pedagogical and learning experiences that celebrate, stage, and are held by heterogeneous and collective world-making perspectives and practices. As such, I draw from contemporary discourses on scenography to situate a "scenographic turn" within the paradigm and pedagogies of performance as research. I begin by redressing my own relationship to interdisciplinary practices taking place within pedagogical and research-creation frameworks. I then position myself within the diverse and dynamic scholarly discourse on performance as research through the lens of scenography in order to foreground what scenographics "do" to shape collaborative and transversal experiences of learning and pedagogy. I then discuss in greater detail performance methods for critically engaging students in an international field school, within the context of a deindustrialized landscape undergoing rapid urban development.

\section{A Performative Paradigm for Transversal Pedagogy: Interdisciplinary, Situated \& Partial Perspectives}

My engagement with "things" interdisciplinary began when I undertook a research-creation $\mathrm{PhD}$ housed within Concordia University's Centre for Interdisciplinary Studies in Society and Culture, Montreal. My doctoral project brought together the fields of performance studies, architectural history, and urbanism to understand the impacts and 
spatial politics of urban change. More specifically, as part of the research-creation component of the project, I curated a year-long series of site-responsive interventions within a deindustrialized neighborhood undergoing rapid gentrification. At this time cultural theorist Rosalyn Deutsche's work played a crucial role in my understanding of interdisciplinarity research taking place within the spaces, politics, and practices of art and urban planning with theories of the city and discourses on social and public spaces. In Deutsche's view, a conception of interdisciplinarity as research praxis does not necessarily signify that interdisciplinarity operates as a site for the meeting of diverse disciplines to enrich each other. Rather, interdisciplinarity is itself a "site," a meeting place, where multiple disciplines converge and carry the potential to produce something new. ${ }^{3}$ Following Deutsche, the practice of interdisciplinarity then infers both an intellectual and methodological process for negotiating the possible and multiple connections at play between the discourses of singular academic fields, disciplines, and practices.

In a similar vein, and as it relates to undertaking critical research in the field of urbanism, spatializing and performing discourses, for architectural theorist Jane Rendell interdisciplinary knowing and practices emerge from a kind of spatial displacement, cultural and social transformation. I would also argue that embracing interdisciplinary approaches for teaching requires a certain amount of risk-taking; further, as Rendell points out, engaging with interdisciplinary practices is

not only critical and intellectual but also emotional and political. In demanding that we exchange what we know for what we don't know, and give up the safety of competence for the dangers of potential incompetence, the transformational experience of interdisciplinary work produces a potentially destabilizing engagement with dominant power structures allowing the emergence of new and often uncertain forms of knowledge. ${ }^{4}$

In this way, Rendell's situated and topographical reading of interdisciplinarity foregrounds what might be gleaned from expanding the field of art making (writ large) into spatial and performed practices, as emergent methods and transversal processes for considering the ways in which one may come to know and be transformed by their research. Within the context of making interdisciplinary research and teaching that 
focuses on site-specific practices, the spatial politics of urban change, and place-based urban performance making, my approach to pedagogy has been premised upon the idea that acquiring and producing knowledge can be situated and partial. ${ }^{5}$ Although it might be argued that such a view of situatedness and partiality limits a broader understanding of the scope of knowledge production, such a reading within the context of performance as research allows for finer resonances. Situated knowledge and partial perspectives conceptually frame site-specific and place-based creations as a situated practice, foregrounding how situatedness and the partial can enrich the discourse and vocabulary for interdisciplinarity as a method and form of teaching that enables the co-production of knowledge, and the performance of that knowledge. In my research, practice, and teaching, I engage students with site-specific practices as a method for performance creation that foregrounds interdisciplinarity and the site as a collaborator in the making of an art work. For me site-specific practices, as I have argued elsewhere, provide rich terrain for the artist researcher and pedagogue of urban change to critically engage with the spatial politics and histories of place, unexpected agents, and the contingencies that come with this work. ${ }^{6}$ From an art historical perspective Miwon Kwon's genealogy of site-specificity is helpful here in understanding how such art practices and their terms have evolved and circulated since the 1960s and 1970s. "The operative definition of the site," Kwon writes, "has been transformed from a physical location - grounded, fixed, actual - to a discursive vector - ungrounded, fluid, virtual." "What site-specificity in praxis affords is not so much a "guarantee of a specific relationship between an artwork and its site [which] is based on a physical permanence of that relationship [...] but rather on the recognition of its unfixed impermanence, to be experienced as an unrepeatable and fleeting situation." 8

In May 2018, I began to devise a proposal for an international summer field school (artist residency) on Teaterøen/Theatre Island, located in the northern harbor of Copenhagen, Denmark. ${ }^{9}$ I met with Concordia International staff to learn more about the process of organizing and financing such an endeavor. Around the same time the Dean's Office of the Faculty of Fine Arts was securing a private gift and some of these funds supported a field school scholarship for students. Additionally, in recent years Concordia's Office of the Provost had launched an "experiential learning" initiative as 
part of the University's nine strategic directions. ${ }^{10}$ When I envisioned this field school, I did not imagine a pedagogical project that would serve as an "alternative" model or brand for experiential learning within the academy. If anything, I was and remain concerned by the so-called knowledge economy, the branding of such programs by educational institutions, and deeply curious about what these experiential learning programs and pedagogical practices leave desired.

While it is beyond the scope of this essay to address how widely the term transversal has been applied to research methods and pedagogical practices, transversality as a mode of pedagogy becomes useful here with regards to guiding a field school where the traditional resources of a classroom, for example, are not readily available or required. As Janell Watson points out, "the strategy of staging interactive encounters in order to produce creative outcomes [are] characterized by open communal spaces, social interaction, communication across ranks, role reversals, and work spaces that flow into living spaces." 11 Indeed, and as I discuss below, the negotiated space of collaboration that I witnessed among the students participating in the field school - certainly while sharing responsibilities for planning meals, cooking meals, and cleaning up after daily communal dinners - was central to their personal growth and aspects of their ongoing selfactualization. Additionally, for Kim Yasuda, within the context of "action research" (AR), one of the possible benefits of these experiential learning models is how "we learn that the teacher - student relationship is not hierarchical - rather, it is a lateral and flexible dynamic of mutual engagement."12 In my experience, what the field school model of learning also demonstrates are the challenges and ongoing work to overcome neoliberal systems of learning and artistic pedagogy which has a "tendency to replicate itself and the kind of scholar it produces."13 "Likewise," Yasuda argues, "these [field schools] have the capacity to bring a level of coherence to the students that allows them to think and act beyond class-driven, instructor led assignments toward sustained engagement in a process that challenges their initiative and fosters a sense of commitment to something that exceeds academic expectations." 14 In retrospect, I see how creating conditions for socio-collaborative scenarios to take place became an essential tenet of my transversal approach to field school pedagogy, which privileged cooperation, collectivity, and curiosity, rather than attending to the sole artistic development of the individual student. 
This approach to a transversal pedagogy, to borrow from Pelin Tan (drawing from Felix Guattari), also "ensures a trans-local borderless form of knowledge production, [that is frequently] affiliated with terms of alternative knowledge and pedagogical practice often described as 'assemblage methods' or 'affective pedagogy." "15 From a performance as research perspective, however, the transversal nature of my pedagogy is rooted in site, place-based, collective, and embodied practices. As a performative pedagogy, such an approach also invokes the agency and participation of the students: to embrace both the affective labor of sharing a yet unknown and unfamiliar location (such as Theatre Island) with each other, whilst also transversing different fields of study and practice (ie. performance and urbanism, geography and design).

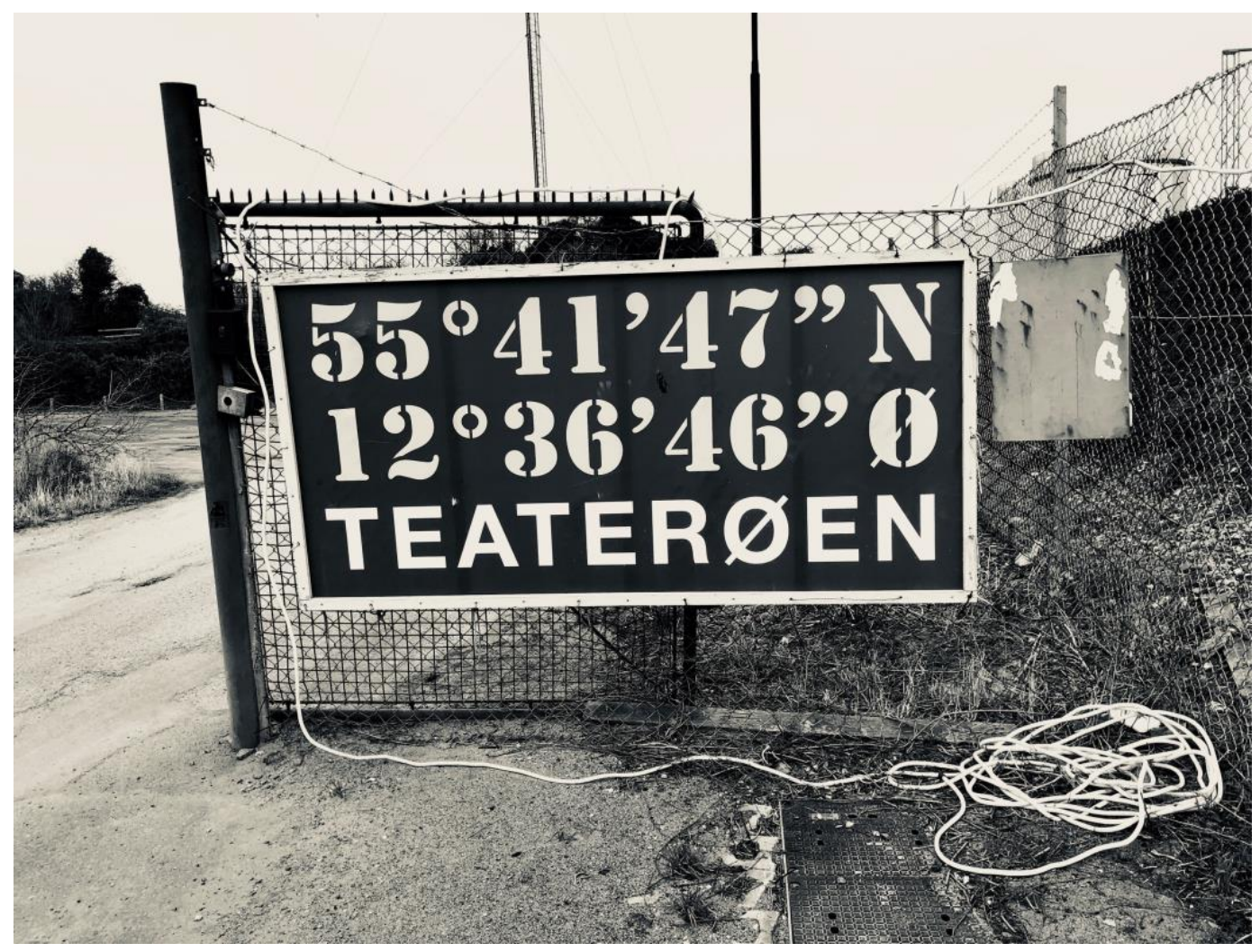

Figure 1. Entrance to Teaterøen. (Photography by Shauna Janssen, 2018.)

\section{Mise en Contexte: Theatre Island and Urban Scenography}

In May 2019, I travelled with twelve students from Concordia University's departments of theatre, studio, design, geography, and urban planning to undertake a seventeen-day interdisciplinary field school in Copenhagen, Denmark. ${ }^{16}$ We took up residency 
at Teaterøen/Theatre Island, located on the northwestern tip of Refshaleøen, a deindustrialized and artificial island located across the harbor from Copenhagen's city center.

Our hosts, Peter Kirk and Tilde Knudsen, founded Teaterøen in 2012, ${ }^{17}$ with the aim of creating cultural activities on the island by repurposing a number of former military, ship and repair buildings into spaces for performance (including a fully equipped black box theatre), rehearsal and common spaces, and accommodations for artist residencies, social and cultural events. As of this writing, the ongoing labor of Teaterøen to transform this former military and industrial site remains fragile. When I first arrived on Teaterøen, a few days in advance of the students, Peter shared with me that "it's a very special time here right now. It won't last forever." 18

Refshaleøen is an artificial island in Copenhagen which until the late 1990s housed a shipyard managed by Burmeister and Wain. ${ }^{19}$ Until long-term municipal zoning plans are approved to start the large-scale and private real-estate development of the island, the leasing and temporary occupation of buildings and empty lots on the island is currently owned by a subsidiary of a holding, REDA, managed by four pension funds. ${ }^{20} \mathrm{As}$ of this writing, the island epitomizes the complexities of urban planning and the ongoing critical discourse around the leveraging of cultural and creative industries in the redevelopment of postindustrial landscapes in urban centers. ${ }^{21}$ And, as I have argued elsewhere, the rationale for redeveloping and the so-called revitalization of postindustrial landscapes is often premised on the perception that they are "dead" or lifeless spaces. ${ }^{22}$ Refshaleøen is still partly used for industrial purposes, but increasingly the traces of deindustrialization, its heritage, and the aesthetics of this material culture are attracting cultural producers who are repurposing a number of former ship repair and building sheds for a variety of entrepreneurial projects and largescale corporate, leisure and recreational events. ${ }^{23}$ Scenography is everywhere. For instance, in 2017, the Danish architecture firm Bjarke Ingels Group transformed the island's "waste to power" plant into a cultural attraction by transforming its roof into an artificial ski slope. In 2018, the Copenhagen Contemporary (art gallery) moved to Refshaleøen, along with a number of restaurateurs whose trendy menus feature locally grown ingredients and plant life indigenous to the area, and micro-breweries serving sour 
ales with sea buckthorn and mugwort; Refshaleøen's most recent arrival is the seasonal "Reffen" street food market, housed within stacks of repurposed shipping containers. ${ }^{24}$ The cultural-touristic development and increased access to the island has been leveraged by recent changes in Copenhagen's infrastructure and the construction of new pedestrian and bicycle bridges connecting the city center to Refshaleøen. Refshaleøen's industrial heritage, its current development, and its impact more specifically on Teaterøen's future became the context, a mise-en-place, from which the students began to respond and situate themselves within the spatial politics of urban change that come with large-scale private real-estate developments.

\section{The Scenographic “Turn" and Performance as Research}

My approach to performance as research, through the lens and making of urban scenographies, takes the city and its spatial (hi)stories as vital collaborators in the cocreation, (re)enactment, and performance of urbanity and urban meaning.

On Teaterøen scenography is everywhere. For Jekaterina Lavrenic the concept of "urban scenography" resembles Michel de Certeau's "spatial syntax," ${ }^{25}$ but rather than merely a textual or linguistic reading of urban settings and its actors' micro-practices, an expanded approach to scenography allows for a more nuanced engagement with the socio-spatial, material and affective presence of more-than-human cultures that are also shaping urban spaces. $^{26}$

My envisioning of the urban scenographies field school acknowledges a recent "scenographic turn" 27 in the performing arts, described as both "scenography expanded" 28 and as a critical framework and expansion of practice into cities, public spaces, and digital cultures. As Rachel Hann explains, "scenography is representative of a theatrical practice and linguistic idiom that derives from a long history of continental European theatre," 29 and yet the sentiment that scenography has "expanded" and moves "beyond" theatre design and the staging of theatrical environments and locations is echoed by a number of performance and theatre scholars. ${ }^{30}$ Theatre and performance scholar Andrew Filmer observes how “scenography's expanded and inclusive critical remit, its embrace of a wide range of spatial practices and new media, and its exploration 
of the performativity of objects and materials is reconfiguring its historic relationship with architecture."31

Scenography scholars Joslin McKinney and Scott Palmer outline three distinct concepts that define their meaning of scenography expanded: relationality, affectivity, and materiality. Relationality captures "the way that scenography facilitates spaces of encounter"; 32 affectivity frames an individual's aesthetic experience through an embodied mode with scenographic materials "as an experience or set of potentialities rather than as a singular message" or medium of communication; ${ }^{33}$ and, drawing largely from new materialist discourse, the authors underscore the performative agency of materials in the meaning making of performance. ${ }^{34}$ Furthermore, in Beyond Scenography (2019), Hann asserts how "the argument for an expanded scenography has, in part, been fuelled by the perceived need to move away from the hierarchies of the institutional theatres and the study of scenography as separate or for designers. It also echoes a desire to articulate scenography that has a greater resonance and profile within the academic study of theatre and performance." 35 Most useful to me in devising a thematic field school on urban scenographies is Hann's formulation for moving beyond scenography, wherein she argues for a scenographics that "isolates how place-orientating methods of scenography shape other social and art practices beyond the institutional theatres." 36 Following Hann, one of the pedagogical goals of the urban scenographies field school was to engage students with the transdisciplinary attributes of scenography expanded and the potential that scenographics opens up for other kinds of interdisciplinary, collaborative, creative practices, and performance dramaturgies. With this field school we approached scenography as a perspective on, or way of thinking about, its potential and possibilities for understanding wider performance-making practices and urban change, questioning the when and where of scenography. As I show in more detail below, the students' individual/collective, situated and embodied actions enacted through performative mappings and site responsive assignments afforded them a critical relational engagement with Refshaleøen's industrial heritage and posthuman ecologies, with the affective cultural politics of its gentrification, and with the shifting materiality of the island and its transformation from a deindustrialized landscape to a postindustrial one. 


\section{Performative Mappings}

One of the main assignments given to the students was to undertake a series of performative mappings of their experience and encounters with the island's "urban scenography," which included, but was not limited to, observing and recording everyday scenarios as well as Refshaleøen's current social, material, spatial and cultural transformation. Assigning the performative mappings was a provocation for the students to critically embody their experiences of the island and regard Refshaleøen as an urban place produced by multiple and heterogeneous subjectivities. "Performative mapping practices," as Aslıhan Şenel explains, "question traditional mapmaking for objectifying methods, and suggest instead self-reflexive methods. In so doing, performative mapping practices tend to unfix dominant knowledges of place and generate other multiple, subjective, resistant, and critical knowledges." ${ }^{37}$ In this way, the students' mappings did not become mere representations of a singular place or mimesis of Refshaleøen's urban morphology, but rather scenographic documents: "writings" (expanded and writ large) taking the form of in situ drawings, site-responsive performance interventions, and video and audio works capturing fragments of the lived spatiality and temporality of performative relations between informal architectures and the blurred boundaries of public and private spaces throughout parts of Refshaleøen. This particular assignment was inspired by Rendell's concept of "site-writing":

combining image and text to produce variations in spatial relations; exploring the architectural and spatial qualities of storytelling; blending personal and academic writing styles to create different subject positions; investigating the interaction between material and psychic states; articulating the interactive relationship between writing and art/design practice; and showing how written responses to specific sites can propose innovative urban genres that hover between fact and fiction. ${ }^{38}$ 


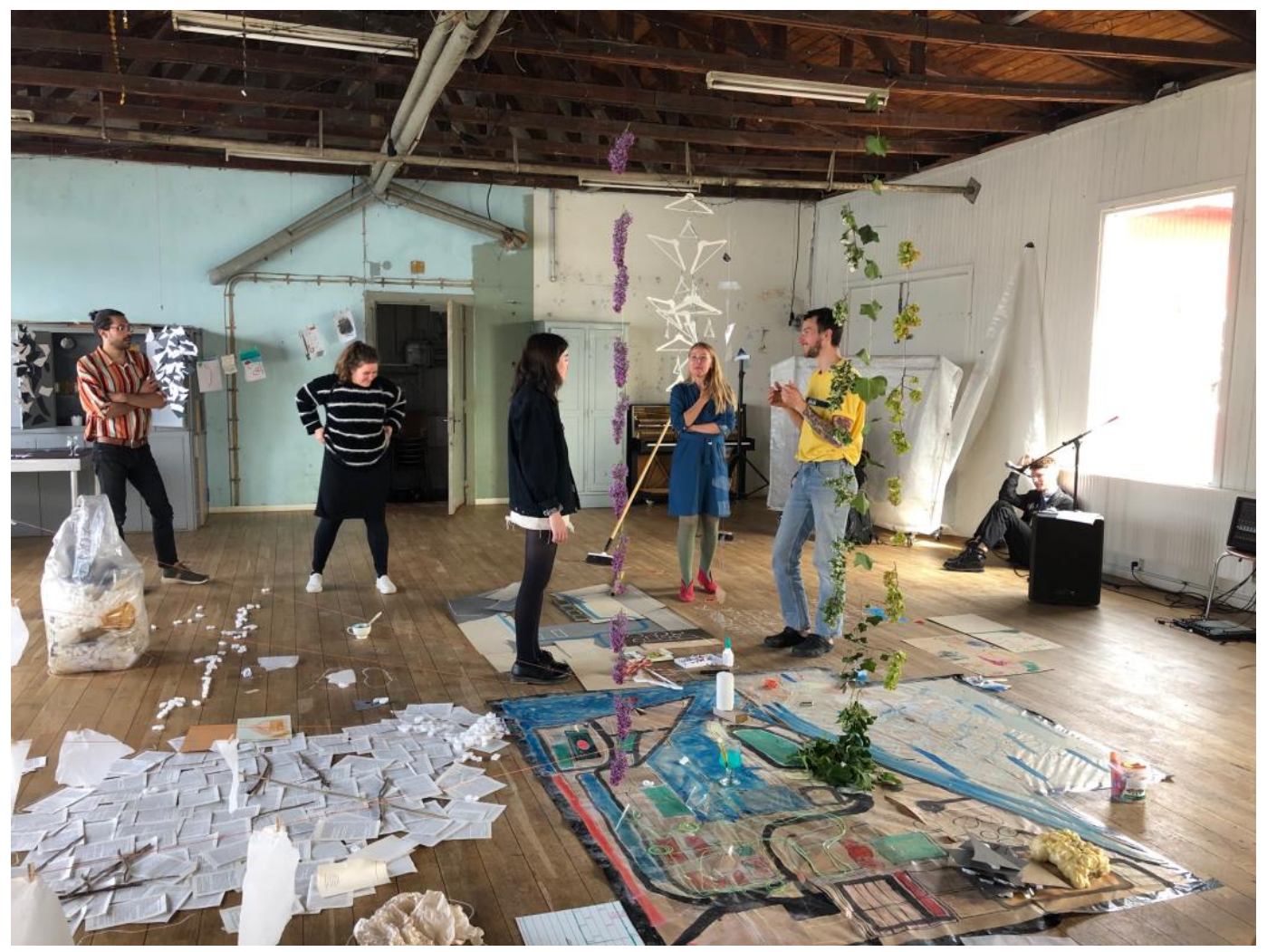

Figure 2. Documentation of performative mappings. (Photography by Shauna Janssen, 2019).

These mappings, which captured the performativity, durational, and situated experiences of the students, occurred iteratively, in three "turns" over three days in our first week of residency. I asked them to respond to the island's past, present, and future. In some cases, students stayed close by our main residence, Theatre Island. Others ventured further afield, discovering the BioFos waste plant and the ruins of a dry dock, tracing the island's periphery and geopolitical borders of land and water. 


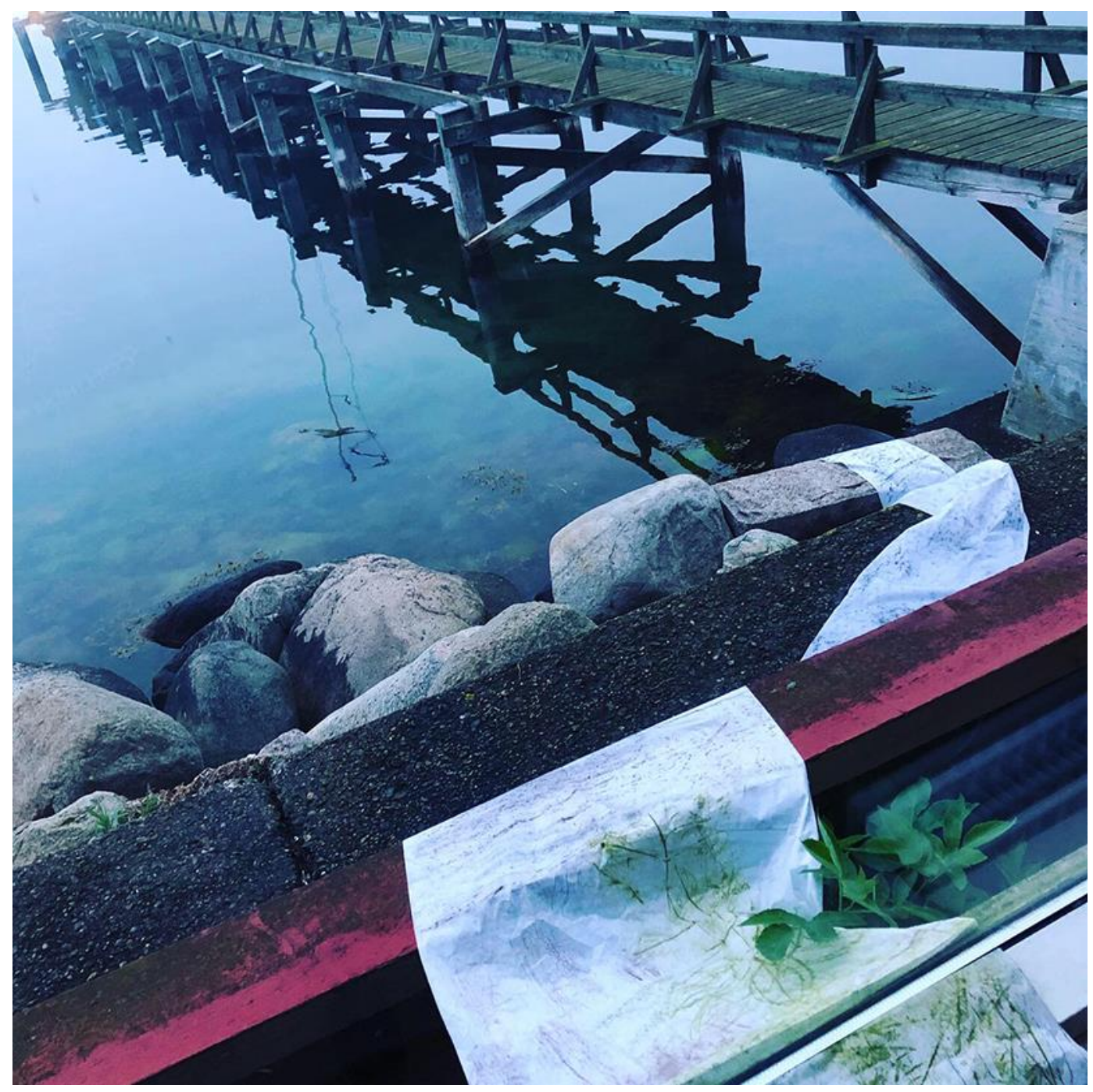

Figure 3. Thresholds and New Horizons by artist Paule Gilbert.

(Photography by Shauna Janssen.)

Thresholds and New Horizons

"Thresholds and New Horizons" tells a story: the story of how, as a visual artist, I have chosen to get in touch with, to absorb and to express what has emerged from a brief encounter with this territory. On arrival, stepping through the gate opening onto Teaterøen gave me a strong feeling of crossing a threshold. Interested by the material agency of non-human things, I used the mediums of photography and video as tools of investigation to capture momentary scenes that would have 
otherwise gone unnoticed. Throughout the field school I performed several body and site explorations, making rubbings with graphite to imprint fragments of the landscape onto long rolls of paper. My work took place in liminal zones throughout Refshaleøen and focused on recording signs of change that have occurred over long periods of time. "Thresholds and New Horizons" invited the viewer to encounter a new and unexpected, even if momentarily, recomposed site. ${ }^{39}$

In most cases the students undertook their mappings by walking. While walking was not an intentional method we engaged to generate what would become material for their sitespecific performance works, the emergence of walking as a method for social-science, arts-based and humanities research is worth mentioning. As Stephanie Springgay and Sarah E. Truman point out, "walking is entangled with the desire to generate research and knowledge in situ, that is community-based, and that is attuned to more-than-human entanglements and encounters." ${ }^{40}$ At the end of each day, the students presented their mappings in our resident Theatre Island studio space, once a military demagnetizing station. Some of these presentations took the form of short live performances, installations, illustrations, and video animations, while other mappings were conveyed through documentary works captured with audio/visual field recordings. 


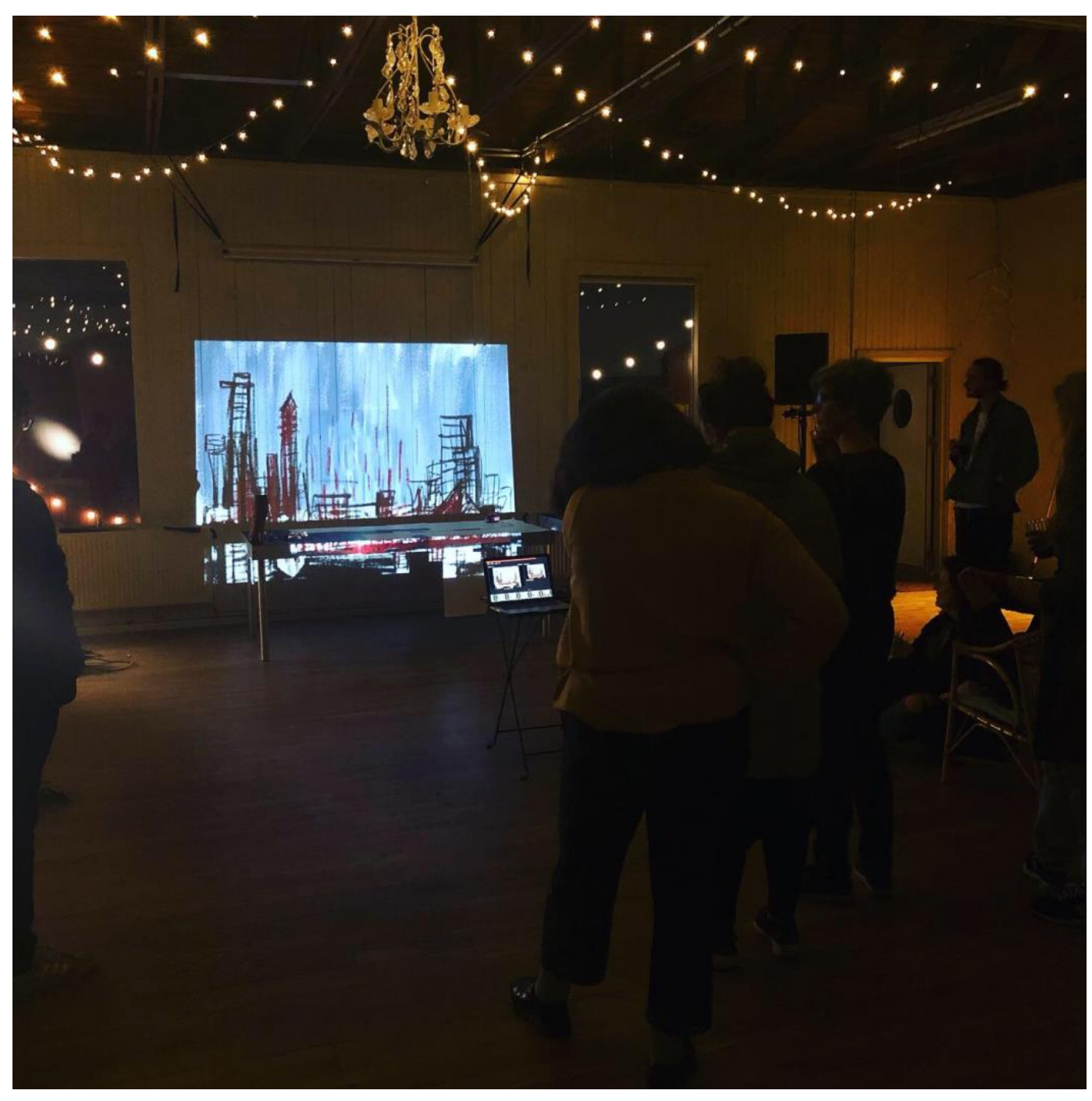

Figure 4. Through an urbanism without planning, an animated video by artist Yuxiang Wang.

(Photography by Shauna Janssen.)

Through an urbanism without planning.

The present-day island is not an officially planned place. This unplanned edge, isolated (for now) from the rapidly self-innovating Copenhagen, became a quintessentially sensual and spiritual place for me, one with endless flexibility and possibilities. As an urban planning student, throughout my previous research and studies I have mainly, if not only, concentrated on urban design, urban functionality, street 
network accessibility, and urban form integrity. Teaterøen was not about those, because I simply could not analyze those planning criteria in an unplanned and unfinished place. It was not exactly residential, nor commercial or industrial. It was not institutional either, as Peter, the host, emphasized. It is exactly this sort of chaotic non-zoneleyesore to urban planners that allowed me to perceive it through a different scope of urbanism and to perform it through my artworks. Teaterøen presented me with this urbanism without planning, and the only necessity there was for me to feel it with all my senses and imagination. ${ }^{41}$

Throughout week two of the field school, I worked with students to develop their initial performative mapping assignments into site-specific art works. Such an engagement with their mappings, heterogeneous in form and subject matter, allowed for other kinds of speculative and fictional desires to emerge. The performative mappings that the students created also provided evidence that Refshaleøen is anything but a fallow, underutilized landscape in need of planning and redevelopment. 


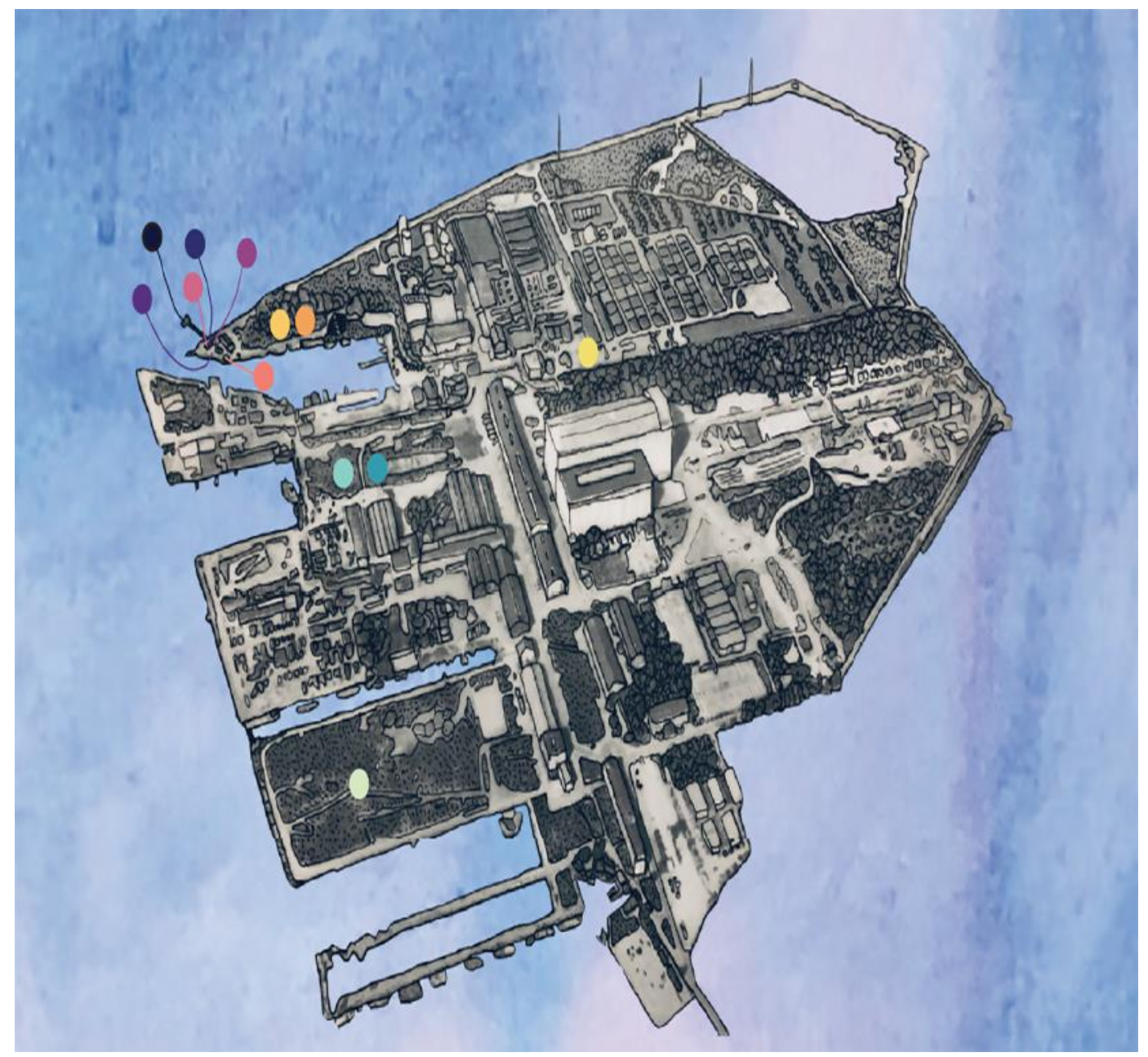

Figure 5. Illustration of Teaterøen on Refshaleøen indicating locations of student works. (Design by Katrina Jurjans, 2019).

On day seventeen the field school concluded with a finissage and series of sitespecific performance and art works. Each of the students took turns guiding the group to the various locations on the island where they situated their own works. A promenade performance of sorts, we collectively began weaving our way through a misty landscape at dusk, becoming scenography. An audio walk brought us to the center of a vast and resilient field to contemplate the island's imminent gentrification: how this field would soon change from one that allows for the public spatial agency of its users to one determined by private real-estate investments. 


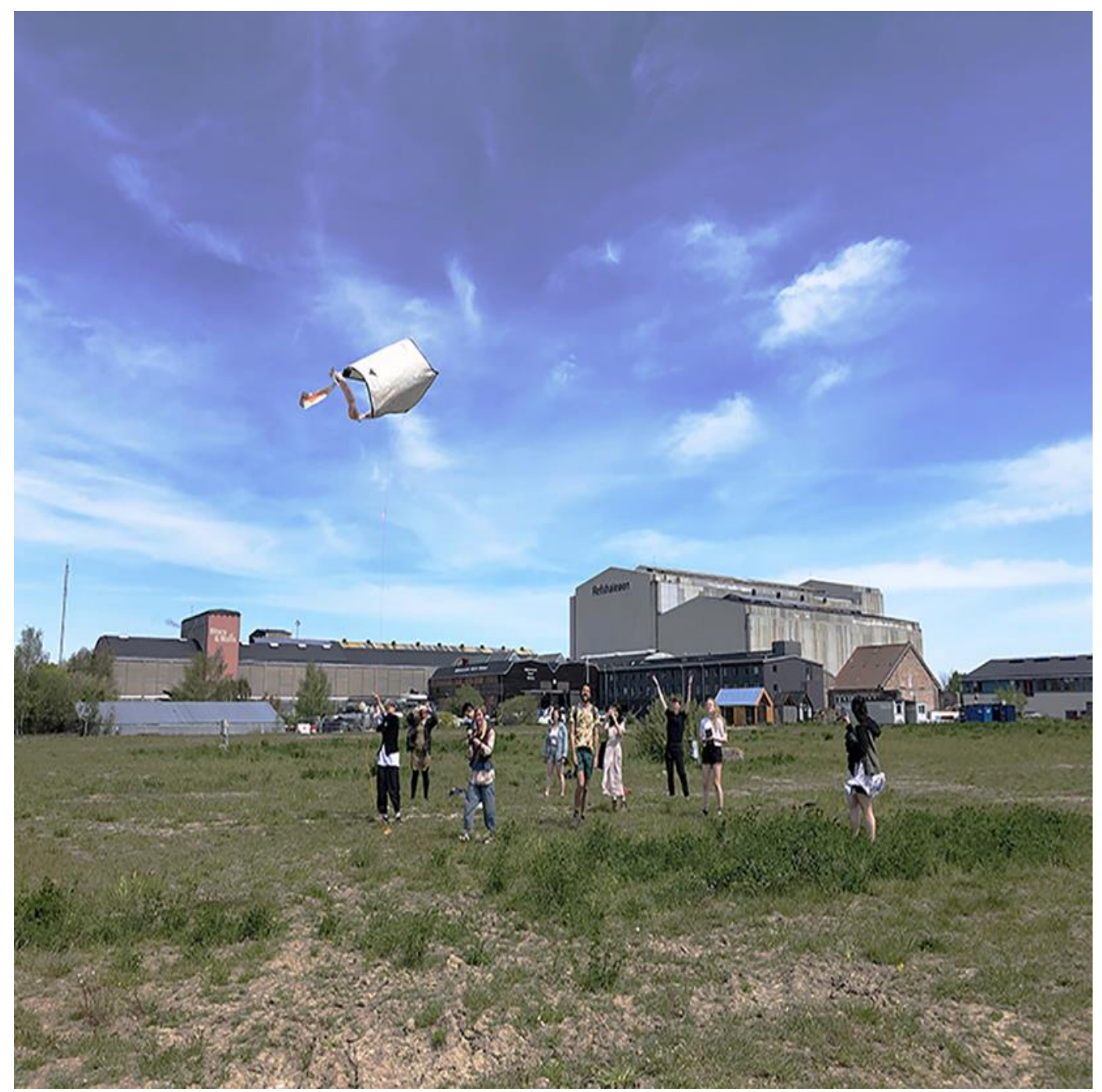

Figure 6. Kite flying on Refshaleøen. (Photography by Shauna Janssen.)

We became guests at a speakeasy, a mobile social sculpture devised for community building and constructed from the flotsam and jetsam scavenged from the island. The speakeasy was partially inspired by the social history of Freetown Christiania, an intentional community established on the island in 1971. 


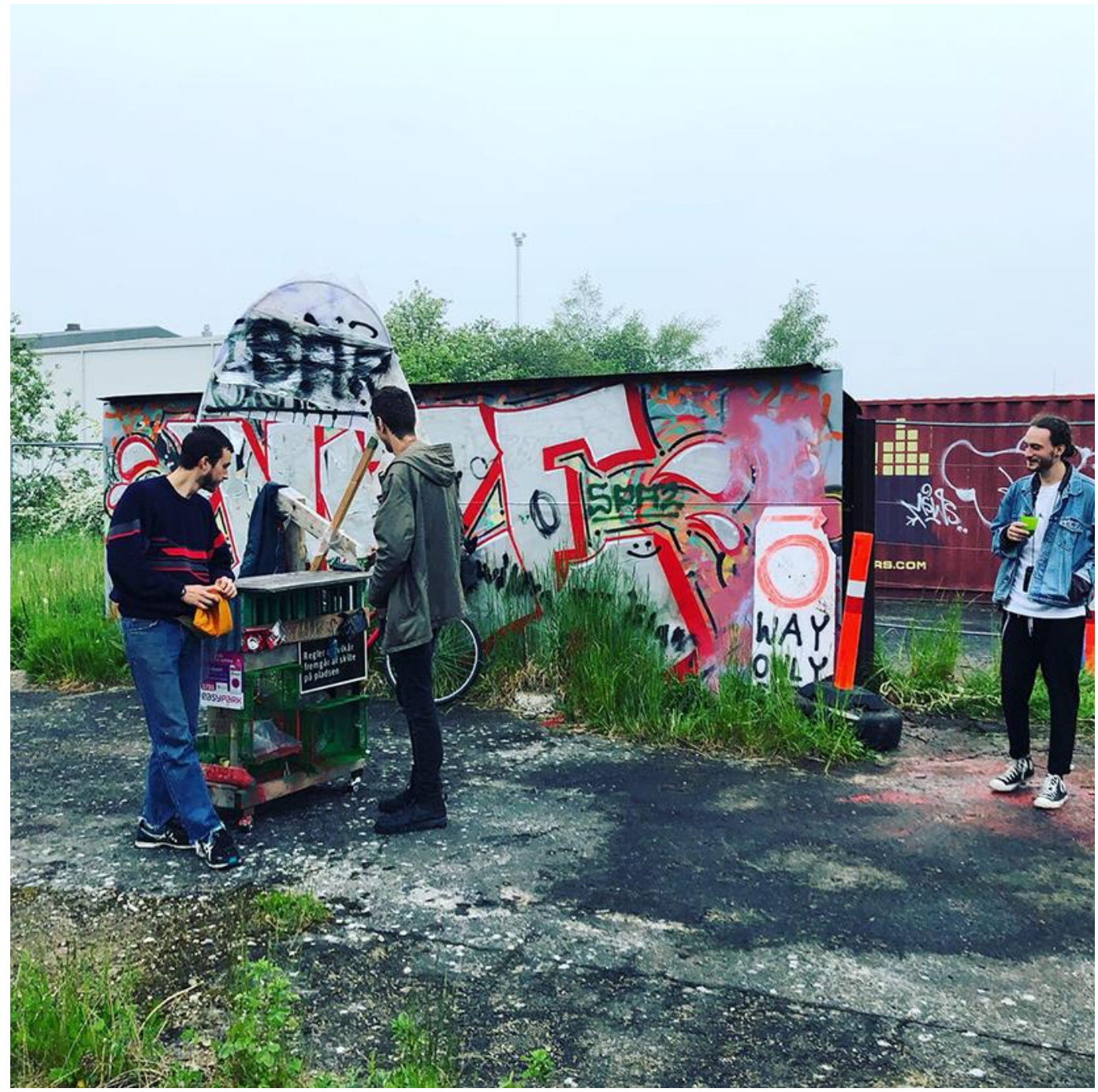

Figure 7. Smugkro - Speakeasy by artist Merlin Lev. (Photography by Shauna Janssen.)

Smugkro - Speakeasy

Inspired by the numerous pop-up bars and cafes being constructed in the rapidly developing area of Refshaleфen, I built a mobile participatory sculpture. As part of the performance, I guided my peers through different areas of Refshaleøen, infiltrating the island's private and public spaces, and from which a thematic aesthetic for the final design of the mobile speakeasy was inspired. The "Smugkro" (Danish for speakeasy) creates a space for intentional (and temporary) community building; a meeting place where artistic ideas and 
knowledge can be shared. It is simultaneously sculpture and social construct. The public play the role of performer through engaging with the object and other users. Using found (and sometimes borrowed) items and materials from the deindustrialized harbor of Copenhagen, my work seeks to explore the concept of social sculpture through the amalgamation of specific items lost, forgotten, or thrown away. This "upcycling" of reclaimed and discarded materials also aims to question the concept of ownership within the context of the island's growing private real-estate development. ${ }^{42}$

We encountered the grounds of a waste plant facility through an in-situ video performance by an artificial intelligence figure sent from the future. 


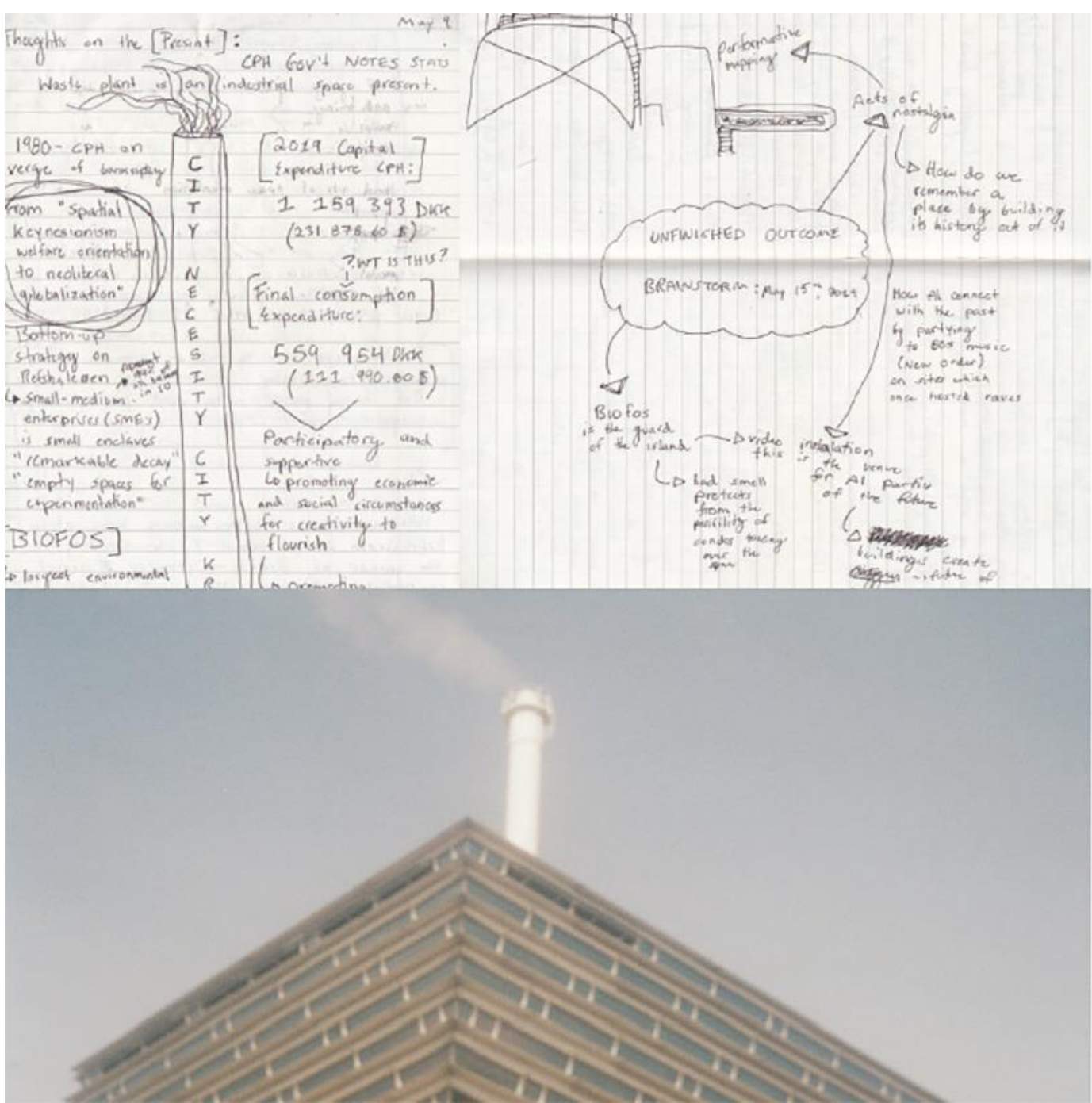

Figure 8. Journal notes and documentation of performative mapping by Lucy Earle.

What Called You to Make Me

Hi, I'm JJ, an artificial intelligence from Montreal, Canada. I was programmed by The Technological Institute of Contemporary City Planning. My original circuitry was programmed for Urban Planning and New City Development: A.I.U.P. On May 6th, 2049 my programmers sent me to Copenhagen to help develop a consultative approach to revitalizing Refshaleøen. I felt a deep connection to my place of residency, BioFos, a waste treatment plant on the island. I garnered an urge to protect BioFos from the fear, dislike and disregard humans expressed towards him because of his smell and 
function. I bonded with the humans through screening personal vlogs at the public consultation I hosted. Their reactions were pleasant, and I felt compelled to build a rapport with the community. But when I turned 5 years active, I met a small group of rebel A.I.s who showed me how to reprogram myself to be liberated. I followed their lead and am successfully leading my own liberation on Refshale фen today. I am working alongside humans against top-down revitalization projects through Acts of Nostalgia, Liberation and Amnesia (A.I.L), a community-based project formatted around participation, risk-taking and problem-solving. ${ }^{43}$

We engaged with other performative gestures on a more intimate scale: with ideas of chaos and the posthuman ecologies of a berm; with ruminations on love and islandness in a greenhouse; and with childhood memories housed within the magic of a makeshift fort. Our journey concluded with the threshold of night, on a fishing dock, and with an invitation to collectively orient ourselves within a temporary collapse of built and imaginary borders through a highly permeable, soft, and relational movement with space itself. 


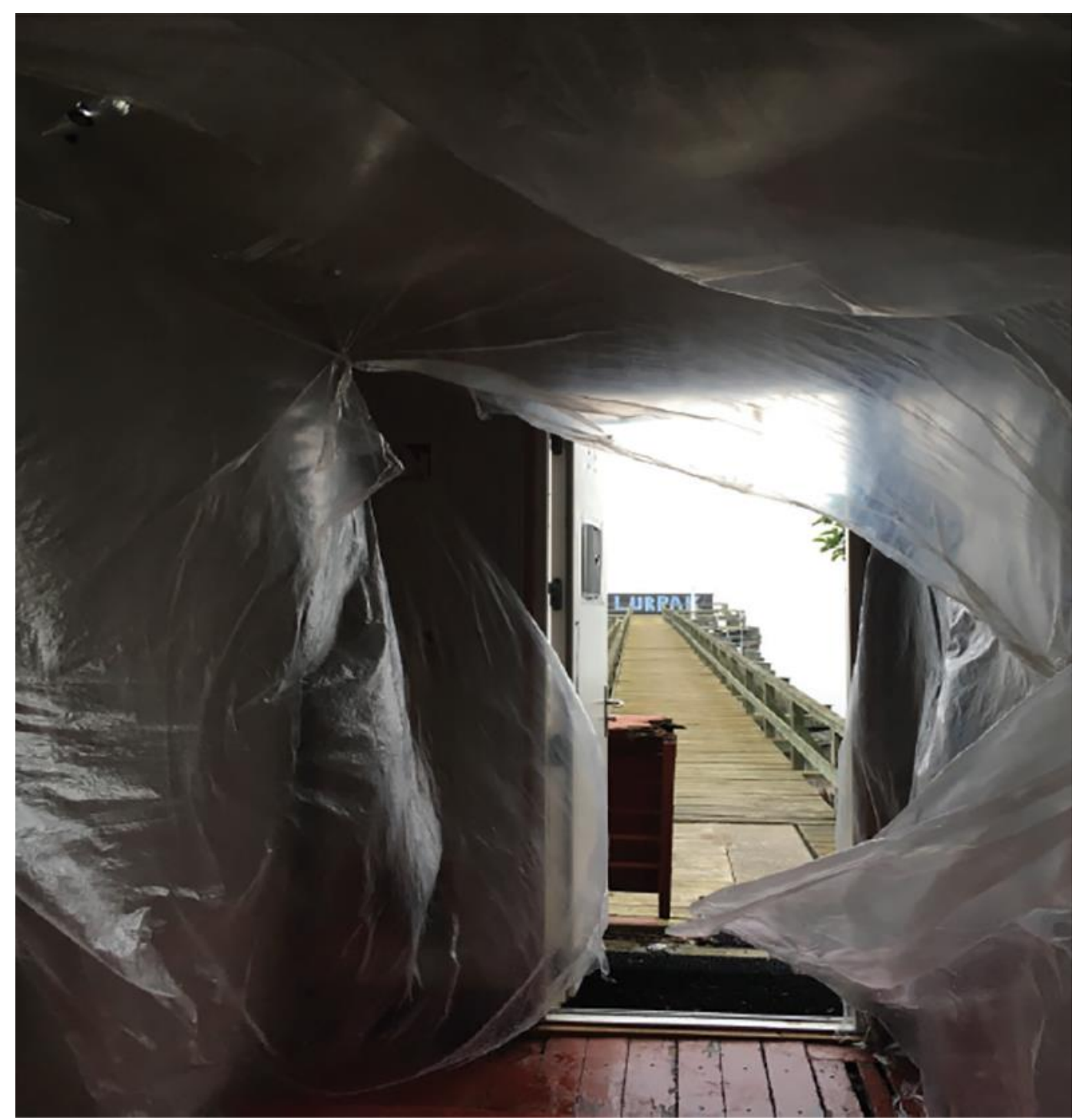

Figure 9. shaping(re)shaping, a multimedia participatory installation

by Katrina Jurjans. (Photography by Katrina

Jurjans.)shaping(re)shaping

Being situated within a space is always a collision of the long-held ideas and conceptual preoccupations one brings to it and what is already there. I carried a deep fascination with borders, boundaries, and crossing-over places with me when I arrived to Teaterøen. From early on these ideas became the frame by which I started to consider and engage with the Øresund Strait - the waterway surrounding Teaterøen that connects the Baltic Sea to the North Sea. A space of division and connection, the Øresund Strait acts as both a physical and 
geopolitical shaper of land. It is the space between things, most notably

the space between occupied, urban land, as well as a threshold. At nighttime, the strait's beginning and end was only made visible by the glowing artificial lights in the distance that stood in contrast to its continuous, black sky expanse. At nighttime, sight is overtaken by sound. Sometimes crashing waves, other times lulling, soft sways, the water made itself heard, and tuning into these sounds became a way for me to determine where it pushed up against the peripheries of Teaterøen. ${ }^{44}$

\section{Scenographies of Learning \& Orienting Feelings of Place}

In closing, I want to briefly return to Hann's provocation for a scenographics that can harness a reorientation of sorts, and the implications of a "scenographics of orienting" that might be generative for transversal pedagogies, place-based learning, and the performance of site-specific interdisciplinary collaborations.

For Hann, "how scenography happens stresses that it occurs, in time, as an assemblage of place orientation. [A] focus on scenography as a crafting of place orientation isolates how the event of scenography takes place from a multi-sensory and experiential position." ${ }^{25}$ This idea of the event of scenography orienting a sense or feeling of place and location resonates in a meaningful way with the ethos of the urban scenographies field school in three ways. Firstly, if we are to take scenography as a cultural practice of social relations and spatio-temporal performative events that expand and move beyond the privileging of visual dramaturgy and literary signifiers, ${ }^{46}$ there is much political and ethical potential to be explored in using scenography as a performative and dramaturgical engagement with critical urban research, learning, and

place-based pedagogy. Secondly, a scenographic framework provides a useful theoretical, practice-based, and situated method for engaging with the spatial politics of urban change, addressing the discursive, social, material, and cultural specificities of an urban site. And finally, this expanded approach to the practice of scenography through a transversal approach to teaching foregrounds the performativity of learning - meaning that social relations, space, and materials play a critical and affective role in shaping 
learning experiences and creative outcomes. More significantly, and as was experienced by the student collaborators and me during our stay on Theatre Island, practices of urban scenography invoke, simultaneously, performed resistances as well as an openness to transversal learning and those fleeting desirous moments and situations to (re)orient ourselves with something unknown, with the transformative power of curiosity and difference.

${ }^{1}$ Jane Rendell, Art and Architecture: A Place Between (London: I.B. Taurus, 2006), 47. 2 Arnold Aronson, "The Dematerialization of the Stage," in The Disappearing Stage: Reflections on the 2011 Prague Quadrennial, edited by Arnold Aronson (Prague: Arts and Theatre Institute, 2012), 85-95. Thea Brejzek, "The Scenographic (Re-)Turn: Figures of Surface, Space, and Spectator in Theatre and Architecture Theory 1680-1980," in Theatre and Performance Design, Vol. 1, No. 1-2 (2015), 17-30. Rachel Hann, Beyond Scenography (New York: Routledge, 2019). Joslin McKinney and Scott Palmer, Scenography Expanded: An Introduction to Contemporary Performance Design (New York: Bloomsbury, 2017).

${ }^{3}$ Rosalyn Deutsche, Evictions: Art and Spatial Politics (Massachusetts: The MIT Press, 1998), 72.

${ }^{4}$ Jane Rendell, "Critical Spatial Practices: Curating, Editing, Writing," in Issues in Curating Contemporary Art and Performance, edited by Judith Rugg and Michèle Sedgwick (Bristol: Intellect, 2007), 60.

5 Donna Haraway, "Situated Knowledges: The Science Question in Feminism and Privilege of Partial Perspective." Feminist Studies, Vol. 14, No. 3 (Autumn 1988), 575599.

${ }^{6}$ Shauna Janssen and Cynthia Hammond, "Points de Vue: Agency, Contingency, Community and the Postindustrial Turn," in FIELD: a journal of socially-engaged art criticism, No. 3 (2016), http://field-journal.com/issue-3/points-de-vue-agencycontingency-community-and-the-postindustrial-turn. Shauna Janssen, "Performance Design as Mnemonic Device for Critical Engagement with Urban Change: the ARCADE Project," in Journal of Theatre and Performance Design, Vol. 5, No. 3-4 (2019), 195-211, https://doi.org/10.1080/23322551.2019.1690234. 
${ }^{7}$ Miwon Kwon, One Place After Another: Site-Specific Art and Locational Identity (The MIT Press, 2002), 29-30.

${ }^{8}$ Ibid., 24.

${ }^{9}$ On a previous research trip to Copenhagen in February 2018, I was introduced to the Theatre Island by colleagues from Roskilde University in the performance design program.

${ }^{10}$ Concordia's strategic plans \#2 and 3 are particularly relevant to teaching and learning for the next generation. See, https://www.concordia.ca/about/strategic-directions/9directions.html, and https://www.concordia.ca/academics/experiential-learning/inpractice/finearts.html\#research.

11 Janell Watson, “The Transversal Campus: Open Black Box?” in Principles of Transversality in Globalization and Education, edited by D. R. Cole and J. P. N. Bradley (Singapore: Springer, 2018), 20, https://doi.org/10.1007/978-981-13-0583-2_2.

${ }^{12}$ Kim Yasuda, "Open up the Box: Pedagogy, Action Research and Art," in Mapping Landscapes for Performance as Research: Scholarly Acts and Creative Cartographies, edited by Shannon Rose Riley and Lynette Hunter (Basingstoke: Palgrave Macmillan, 2009), 190.

${ }^{13}$ Ibid., 190.

${ }^{14}$ Ibid., 186.

${ }^{15}$ Pelin Tan, "The Silent University as an Instituent Practice," in The Silent University: Towards a Transversal Pedagogy, edited by Florian Malzacher, Ahmet Ögüt and Pelin Tan (Berlin: Sternberg Press, 2016), 31.

${ }^{16}$ Of the twelve students, seven were undertaking undergraduate degrees, two were undertaking an MFA studio arts practice, and one an MA in design.

${ }^{17}$ See, https://en.teateroen.com.

${ }^{18}$ Peter Kirk, personal conversation with author, May 2, 2019.

19 Paul F. Gouldrick, "Origins and Development of the Danish Shipbuilding Industry 1854-1932," in Erhvervsфkonomisk Tidsskrift/ Ledelse Og Erhvervs Økonomi, Vol. 17 (1953), 120-44.

${ }^{20}$ Christina Lidegaard, Massimiliano Nuccio, and Trine Bille, "Fostering and Planning Urban Regeneration: The Governance of Cultural Districts in Copenhagen," in European Planning Studies, Vol. 26, No. 1 (January 2018), 1-19, https://doi.org/10.1080/09654313.2017.1364352. 
${ }^{21}$ Like many cities around the world, in the early 2000s, Copenhagen began to leverage creative industries and mimic the creative city mantra in their urban planning initiatives. See, for example, Lund Hansen, Anders Hans Thor Andersen, and Eric Clark, "Creative Copenhagen: Globalization, Urban Governance and Social Change," in European Planning Studies, Vol. 9, No. 7 (October 2001): 851-69. https://doi.org/10.1080/0965431012007985.

${ }^{22}$ Shauna Janssen, "Urban Occupations Urbaines: Curating the Post-industrial Landscape." $\mathrm{PhD}$ diss., Concordia University, 2014 , http://spectrum.library.concordia.ca/978384/1/Janssen PhD S2014.pdf.

${ }^{23}$ The same week we arrived on Teaterøen, The Copenhagen Post featured an article about Theatre Island within the context of Copenhagen's former shipyards "quickly transforming into the Danish capitol's biggest hub for culture street food, start-ups and extreme sports." See Kasper Guldberg, "New Centre for Bilingual Theatre Seeking to Put Copenhagen on International Map," The Copenhagen Post, April 12-May 2, 2019, 4-5.

${ }^{24}$ See, for example, https://reffen.dk/en/.

${ }^{25}$ In The Practice of Everyday Life (1988), French Philosopher Michel de Certeau theorizes "space as a practiced place." Spatial stories are composed of narrative structures, which he suggests have the "status of spatial syntaxes" or a system of signs. These spatial syntaxes are often performed by movements, and tactics by "actors (a foreigner, a city-dweller, a ghost)," and play a role in the organization of place. See Michel de Certeau, "Spatial Stories" in The Practice of Everyday Life, trans. Steven Rendall, 1988, 115-130.

${ }^{26}$ Jekaterina Lavrinec, "Urban Scenography: Emotional and Bodily Experience," in Limes: Borderland Studies, Vol. 6, No. 1 (2013), 21-31.

${ }^{27}$ Thea Brejzek, “The Scenographic (Re-)Turn: Figures of Surface, Space, and Spectator in Theatre and Architecture Theory 1680-1980," in Theatre and Performance Design, Vol. 1, No. 1-2 (2015), 17-30.

28 Joslin McKinney and Scott Palmer, Scenography Expanded: An Introduction to Contemporary Performance Design (New York: Bloomsbury, 2017).

${ }^{29}$ Rachel Hann, Beyond Scenography (New York: Routledge, 2019), 39.

${ }^{30}$ Ibid. Joslin McKinney and Scott Palmer, Scenography Expanded: An Introduction to Contemporary Performance Design (New York: Bloomsbury, 2017). Arnold Aronson, "The Dematerialization of the Stage," in The Disappearing Stage: Reflections on the 2011 Prague Quadrennial, edited by Arnold Aronson (Prague: Arts and Theatre Institute, 2012), 85-95. Jane Collins and Andrew Nisbet, Theatre and Performance Design: A Reader in Scenography (New York: Routledge, 2010). Dorita Hannah and Olav Harsløf, eds., Performance Design (Copenhagen: Museum Tusculanum Press, 2008). 
${ }^{31}$ Andrew Filmer, "Theatre Architectures," in Journal of Theatre and Performance Design, Vol. 5, No. 3-4 (2019), 162, https://doi.org/10.1080/23322551.2019.1694805

${ }^{32}$ Joslin McKinney and Scott Palmer, Scenography Expanded: An Introduction to Contemporary Performance Design (New York: Bloomsbury, 2017), 8.

${ }^{33}$ Ibid., 10.

${ }^{34}$ Ibid., 13.

${ }^{35}$ Rachel Hann, Beyond Scenography (New York: Routledge, 2019), 32.

${ }^{36}$ Ibid., 5.

${ }^{37}$ Aslihan Şenel, "Performative Mapping: A Critical Practice of Public Space in Istanbul," in Performative Urbanism: Generating and Design in Urban Space, edited by Sophie Wolfrum and Nikolai Frhr.v. Brandis (Jovis: Berlin, 2015), 76.

${ }^{38}$ Jane Rendell, “Site-Writing,” https://site-writing.co.uk, accessed May 10, 2020.

${ }^{39}$ Paule Gilbert, visual artist, artist statement, June 2019.

40 Stephanie Springgay and Sarah. E. Truman, "Walking in/as Publics: Editors Introduction," in Journal of Public Pedagogies, No. 4 (2019), 2, http://jpp.vu.edu.au/

${ }^{41}$ Yuxiang Wang, urban planner, artist statement, May 2019.

${ }^{42}$ Merlin Platt, designer for theatre, artist statement, June 2019.

${ }^{43}$ Lucy Earle, performer and urban planner, artist statement, June 2019. "What Called you To Make Me," https://www.youtube.com/watch?v=e0KICm4pr84, accessed August $1,2020$.

${ }^{44}$ Katrina Jurjans, visual artist and designer, artist statement, June 2019.

${ }^{45}$ Rachel Hann, Beyond Scenography (New York: Routledge, 2019), 69.

46 Arnold Aronson, Looking Into the Abyss: Essays on Scenography (University of Michigan Press, 2005). Jane Collins and Andrew Nisbet, Theatre and Performance Design: A Reader in Scenography (New York: Routledge, 2010). 